
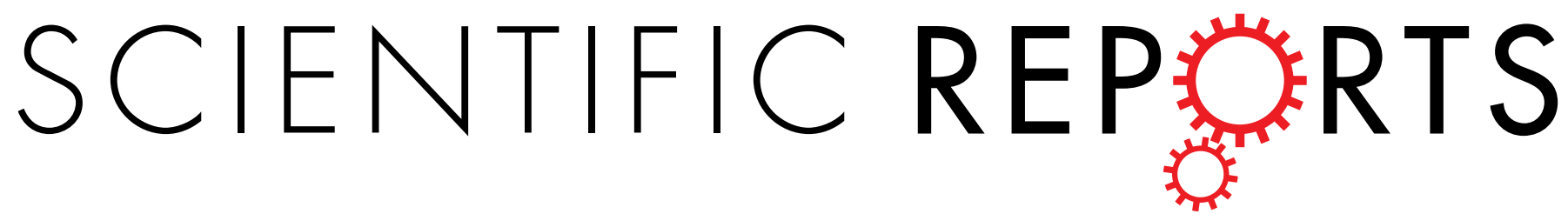

\title{
OPEN
}

Received: 21 June 2017

Accepted: 17 August 2017

Published online: 12 September 2017

\section{Structural and functional insights} into the periplasmic detector domain of the GacS histidine kinase controlling biofilm formation in Pseudomonas aeruginosa

\author{
Ahmad Ali-Ahmad ${ }^{1}$, Firas Fadel ${ }^{1,2}$, Corinne Sebban-Kreuzer ${ }^{2}$, Moly Ba², Gauthier Dangla \\ Pélissier (iD ${ }^{2}$, Olivier Bornet ${ }^{2}$, Françoise Guerlesquin ${ }^{2}$, Yves Bourne $^{1}$, Christophe Bordi ${ }^{2}$ \& \\ Florence Vincent $\mathbb{D}^{1}$
}

Pseudomonas aeruginosa is an opportunistic pathogenic bacterium responsible for both acute and chronic infections and has developed resistance mechanisms due to its ability to promote biofilm formation and evade host adaptive immune responses. Here, we investigate the functional role of the periplasmic detector domain $\left(\mathrm{GacS}_{\mathrm{PD}}\right.$ ) from the membrane-bound GacS histidine kinase, which is one of the key players for biofilm formation and coordination of bacterial lifestyles. A gacS mutant devoid of the periplasmic detector domain is severely defective in biofilm formation. Functional assays indicate that this effect is accompanied by concomitant changes in the expression of the two RsmY/Z small RNAs that control activation of GacA-regulated genes. The solution NMR structure of $\mathrm{GacS}_{\mathrm{PD}}$ reveals a distinct PDC/PAS $\alpha / \beta$ fold characterized by a three-stranded $\beta$-sheet flanked by $\alpha$-helices and an atypical major loop. Point mutations in a putative ligand binding pocket lined by positively-charged residues originating primarily from the major loop impaired biofilm formation. These results demonstrate the functional role of GacS $_{P D}$, evidence critical residues involved in GacS/GacA signal transduction system that regulates biofilm formation, and document the evolutionary diversity of the PDC/PAS domain fold in bacteria.

To cope with environmental changes and develop colonization strategies, bacteria have evolved several sensing systems, including cell-surface signaling systems, quorum sensing, cyclic di-GMP, and the predominant two-component signal-transduction systems (TCS). By modulating cellular functions in response to environmental changes, TCSs play essential roles for the adaptation and survival of organisms ${ }^{1,2}$. Typically, a TCS comprises a membrane-embedded histidine kinase sensor (HK), which acts mainly as a dimeric assembly, and a cognate response regulator (RR). Detection of an environmental stimuli by the HK detector domain triggers autophosphorylation of the HK cytoplasmic domain ${ }^{3,4}$, leading to activation of a phosphorelay mechanism ending onto the cognate RR to mediate expression of various target genes ${ }^{5}$.

P. aeruginosa is a major opportunistic pathogen, responsible for nosocomial infections causing severe infections in vulnerable patients such as those with cystic fibrosis or hospitalized with cancer, severe burns and in intensive care units. P. aeruginosa is able to switch from a planktonic (free swimming) to a sessile (biofilm) lifestyle and several TCSs play a critical role in controlling this switch ${ }^{6,7}$. In the free-swimming state responsible for acute infection, bacteria can cross host barriers and proliferate inside the host using motility and virulence factors that are secreted in the extracellular space or directly injected into the host cells using the type III secretion systems ${ }^{8}$. Chronic infection is characterized by formation of an antibiotic-resistant biofilm in which intricate bacterial communities are embedded within a matrix of exopolysaccharides and $\mathrm{DNA}^{9}$. In this particular state, bacteria concomitantly secrete toxins delivered by the type VI secretion system (H1-T6SS), which are used to kill and compete with other species in a crowded and enclosed community ${ }^{10-13}$.

${ }^{1}$ CNRS, Aix Marseille Univ, AFMB, Marseille, France. '2 LISM, IMM, Aix-Marseille Univ and CNRS, Marseille, 13402, France. Ahmad Ali-Ahmad and Firas Fadel contribute equally to this work. Correspondence and requests for materials should be addressed to C.B. (email: bordi@imm.cnrs.fr) or F.V. (email: florence.vincent@afmb.univ-mrs.fr) 
Many reports have described a balance between expression of molecular determinants involved in chronic infection (biofilm) and those involved in acute infection (cytotoxicity). In P. aeruginosa, the HK/RR pair made by the GacS/GacA TCS, which plays a central role for controlling the transition state between the two infection types, is antagonistically modulated by three other histidine kinase sensors LadS, RetS, and PA $1611^{14,15}$. The calcium-responsive LadS HK activates GacA by using GacS as a direct phosphorelay mechanism to promote chronic infection ${ }^{16,17}$. Conversely, the RetS HK blocks GacA activation by impeding GacS autophosphorylation to promote acute infection ${ }^{18}$. In this regulatory scheme, the PA1611 HK permits GacS activation by preventing the interfering effects of the RetS HK on the GacS signalling pathway ${ }^{19,20}$.

Within the HK family, activation of this phosphorylation cascade requires recognition of an external signal molecule by a highly variable detector domain, which can be embedded in the cytoplasmic, the inner membrane or the periplasmic space ${ }^{3,4}$. The nature of the signal sensed by the HKs are broad and can include nutriments, ions, temperature or redox state ${ }^{21}$. During the last decade, several detector domains have been characterized and various structural families have been proposed despite sequence discrepancy. In turn, three large families of detector domains have been defined according to sequence similarity and fold: 1 - an $\alpha$-helical fold like the $E$. coli NarX detector domain, 2- a $\beta$-sheet fold like the P. aeruginosa RetS periplasmic detector domain and 3- a mixed $\alpha / \beta$ fold named PAS-like/PhoQ, DcuS and CitA (PDC) domain ${ }^{3,22-24}$.

The GacS HK harbors a N-terminal transmembrane $\alpha$-helix, followed by a periplasmic detector domain $\left(\mathrm{GacS}_{\mathrm{PD}}\right)$ tailed by a second transmembrane $\alpha$-helix connected to a large cytoplasmic region ${ }^{25}$. Unlike classical HKs made of a single cytoplasmic transmitter domain (H1), the unorthodox GacS HK consists of a transmitter domain (H1) linked to the two phosphotransfer receiver (D1) and transmitter (H2) domains. Once activated, the GacA RR positively and exclusively controls expression of two unique target genes encoding the two small noncoding RsmY and RsmZ RNAs ${ }^{26}$. These two RsmY and RsmZ RNAs sequesters the small RNA-binding protein RsmA, a translational repressor of genes regulating biofilm, such as the polysaccharide $p e l$ and $p s^{27,28}$, the type VI secretion system (H1-T6SS) and associated virulence factors, or cytotoxicity such as the type III secretion system $(\mathrm{T} 3 \mathrm{SS})^{29,30}$

The GacS HK possesses a periplasmic 126-residue detector domain which is proposed to recognize a yet unknown signal and transmit structural rearrangements onto the transmembrane helices, leading to activation of the phosphorelay cascade ${ }^{25}$. While the series of events occurring in this regulatory mechanism have been well documented at the molecular level, as exemplified by the calcium-responsive LadS $\mathrm{HK}^{17}$, the architecture of $\mathrm{GacS}_{\mathrm{PD}}$ and the molecular determinants underlying signal response remain to be investigated. Here, we report the functional and structural characterization of $P$. aeruginosa $\mathrm{GacS}_{\mathrm{PD}}$. We show that a $P$. aeruginosa mutant strain lacking $\mathrm{GacS}_{\mathrm{PD}}$ exhibits altered biofilm formation and rsm gene expression. The solution nuclear magnetic resonance (NMR) structure of $\mathrm{GacS}_{\mathrm{PD}}$ reveals an atypical PDC/PAS-like domain fold that consists of a 3-stranded $\beta$-sheet flanked by $3 \alpha$-helices on one face and a major loop region on the opposite face. Mapping of conserved surface-exposed residues identifies a putative functional pocket that could act as a ligand-binding site created primarily by residues from the major loop. NMR relaxation experiments indicate that this major loop is conformationally dynamic in solution, suggesting that ligand-induced conformational changes may occur. Mutation of three residues lining this putative binding pocket causes severe defects in biofilm formation and $r s m$ genes expression, suggesting a functional role of these residues in the downstream GacS/GacA signal transduction system. Overall, these results unveil the functional role of $\mathrm{GacS}_{\mathrm{PD}}$ and document the evolutionary diversity of PDC/PAS domain fold in bacteria. They provide new insights into the central role of the P. aeruginosa GacS/GacA TCS to control bacterial lifestyle through the GacS-mediated signaling transduction mechanism.

\section{Results and Discussion}

The GacS periplasmic detector domain is required for GacS function. To evaluate the functional role of the $\mathrm{GacS}_{\mathrm{PD}}$ domain in activation of the GacS/GacA signaling pathway in P. aeruginosa, we performed phenotypic analysis related to biofilm formation using the PAKgacS $\Delta_{P D}$ strain harboring a GacS HK variant lacking 102 residues, of the periplasmic detector domain (Table S1). The PAKgacS $\Delta_{P D}$ strain exhibits severe defects in biofilm formation as determined by crystal violet staining, a phenotype similar to the PAK $\Delta$ gacS mutant strain (Fig. 1a). To better quantify the amount of biofilm produced by the PAKgac $S \Delta_{P D}$ strain, we in-depth analyzed the biofilm morphology of the three WT, PAK $\Delta g a c S$ and PAKgacS $\Delta_{P D}$ strains by confocal laser scanning microscopy using DAPI-labelled cells (Fig. 1b). Consistent with the crystal violet-based assay, biofilm image analysis of the PAKgacS $\Delta_{P D}$ strain evidences a lack of biofilm structure reminiscent of the PAK $\Delta$ gacS strain, corresponding to around 4-fold reduction in biofilm thickness compared to a compact multilayer structure of the WT PAK strain (Fig. 1b). Next, we examined whether deletion of $\mathrm{GacS}_{\mathrm{PD}}$ impairs the GacS/GacA TCS signaling pathway. We thus monitored the expression profiles of the two $r s m Z$ and $r s m Y$ genes by introducing the $r s m Y-l a c Z$ and $r s m Z$-lacZ transcriptional fusions in the PAKgac $S \Delta_{P D}$ strain. Analysis of the level of $\beta$-galactosidase activity, measured at various growth stages, revealed a reduced $r s m Y$ and $r s m Z$ promoter activity in the PAKgacS $\Delta_{P D}$ strain compared to the parental WT PAK strain (Fig. 2a). Hence, expression level of the two sRNAs was decreased by 61 -fold and 11-fold for $r s m Y$ and $r s m Z$, respectively, in the gacS $\Delta_{\mathrm{PD}}$ mutant PAK strain compared to the WT strain (Fig. 2a). Since up-regulation of $r s m Y$ and $r s m Z$ genes leads to T3SS repression and T6SS up-regulation ${ }^{14,31}$, we also examined whether a PAKgacS $\Delta_{P D}$ mutant strain could affect T3SS or T6SS expression. By monitoring expression level of $\operatorname{vgrG1b}$ or exoS, which are two specific components of T6SS and T3SS, respectively, we found a 6.1-fold induction of T3SS associated to a 7.1-fold repression of T6SS in the GacS $\Delta_{\mathrm{PD}}$ HK variant (Fig. 2b), consistent with a similar expression level of these two components in the PAK $\Delta$ gacS strain.

To evidence the functionality of the GacS variant lacking the periplasmic detector domain produced by the PAKgacS $\Delta_{\mathrm{PD}}$ strain, we checked the capacity of the LadS HK to activate expression of $r s m$ genes. We had previously reported that the cytoplasmic region of GacS HK is required for the LadS HK to activate biofilm formation and expression of $r s m Y$ and $r s m Z$ genes ${ }^{16}$. Thus, we overexpressed the full-length LadS protein using 
a.

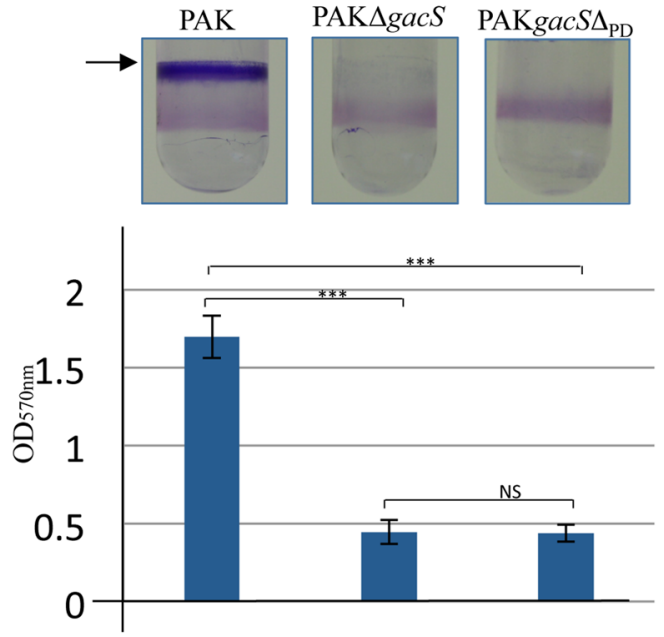

b.

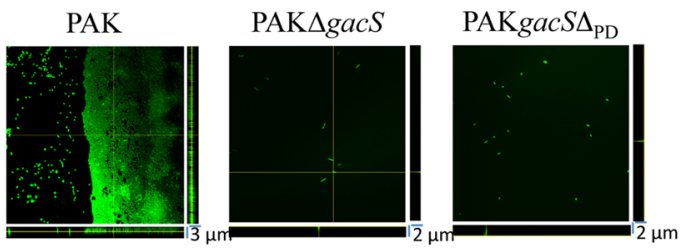

Figure 1. Deletion of the GacS periplasmic detection domain affects biofilm formation. (a) Biofilm production in glass tubes (upper panel) is illustrated and quantified after crystal violet-staining (lower panel). Biofilm levels represent mean values (with error bars) obtained from three independent experiments. *, **, *** and ns refer to $\mathrm{p}<0.05, \mathrm{p}<0.01, \mathrm{p}<0.001$ and non-significant difference, respectively, according to the WilcoxonMann-Whitney tests. (b) Biofilm formation is monitored by confocal laser scanning microscopy after $12 \mathrm{~h}$. The extracted $\mathrm{z}$ images and their respective $\mathrm{xy}$ and $\mathrm{xz}$ planes are shown.

the pBBRladS plasmid in the WT, PAK $\Delta$ gacS and PAKgacS $\Delta_{P D}$ strains containing the rsm Y-lacZ or rsmZ-lacZ fusion. Overexpression of LadS results in a significant increase of biofilm formation and activity of both $r s m$ fusions in the WT and PAKgacS $\Delta_{\mathrm{PD}}$ strains (Fig. S1), suggesting that a GacS variant lacking the periplasmic detector domain is responsive to LadS activation. Taken together, these data demonstrate the functional role of the GacS periplasmic dectector domain to activate the GacS/GacA signaling pathway and modulate expression of the two rsm genes for production of the T3SS or T6SS effectors. The fact that the GacS periplasmic domain from the root-colonizing $P$. fluorescens $\mathrm{CHA} 0$ strain was shown to not have essential activity for the GacS/GacA signaling pathway ${ }^{32}$ argues for possible different functions within a group of evolutionary-related proteins. We thus generated a phylogenic tree using 227 sequence homologues of the GacS periplasmic detector domain (Fig. S2). As evidenced by the phylogenic tree, the periplasmic domains of $P$. fluorescens and P. aeruginosa GacS appear to have early diverged within a Pseudomonas group reinforcing the hypothesis that these proteins can evolve a new or modified function. This is consistent with the recent observation that even closely related LadS orthologues are unable to sense calcium pointing to the acquisition of new functions by the periplasmic detector domains during evolution of this HK family ${ }^{10}$.

The NMR solution structure of $\mathrm{GacS}_{\mathrm{PD}}$ reveals a distinct PDC $\alpha / \beta$ fold domain. To decipher the architecture and functional determinants of $\mathrm{GacS}_{\mathrm{PD}}$ (Met38-Gly164), a construct harboring an N-terminal TEV-cleavable $\mathrm{His}_{6}$-tag was expressed in E. coli and purified as previously reported ${ }^{33}$. Size-exclusion chromatography (SEC)-MALS analysis reveals a dominant monomeric population with an estimated molecular weight of $15 \mathrm{kDa}$ (Fig. S3). ${ }^{15} \mathrm{~N}$ - and ${ }^{13} \mathrm{C}$-labelled $\mathrm{GacS}_{\mathrm{PD}}$ produced in ${ }^{15} \mathrm{~N}$ and ${ }^{13} \mathrm{C}$-labelled minimal medium was used to achieve a complete resonance assignment of $\mathrm{GacS}_{\mathrm{PD}}$ obtained using standard multidimensional triple resonance NMR experiments ${ }^{33}$.

The $\mathrm{GacS}_{\mathrm{PD}}$ solution structure is based on 1299 non-redundant and unambiguously nuclear Overhauser effect (NOE)-derived distance restraints, 94 dihedral angle restraints and 27 hydrogen bond restraints (Table S2). The final ensemble of 20 best low-energy NMR structures has a rmsd value of $0.95 \AA$ for the backbone (N, C $\alpha$ and Co) atoms, and exhibits no obvious NOE violations and dihedral violations $>0.5 \AA$. The rmsd value of backbone residue atoms in regular secondary structure elements is $0.35 \AA$ for 524 atoms.

The $\mathrm{GacS}_{\mathrm{PD}}$ solution structure consists of a central three-stranded antiparallel $\beta$-sheet flanked by three $\mathrm{N}$-terminal $\alpha$-helices on one side and a major loop on the opposite side. The $\alpha 3-\beta 1 / 2$-loop- $\beta 3$ topology found in $\mathrm{GacS}_{\mathrm{PD}}$ is reminiscent of the $\alpha 3-\beta 2-\alpha 1 / 2-\beta 3-\alpha$ topology found in other extracytoplasmic PDC/PAS domains (Fig. 3). In fact, the $\mathrm{GacS}_{\mathrm{PD}}$ three-stranded $\beta$-sheet differs from the extended five-stranded $\beta$ sheet typically found in canonical PDC/PAS fold structures ${ }^{34}$ (Fig. S4). The major 49-residue length loop (Gly99-Leu148), which 
a.
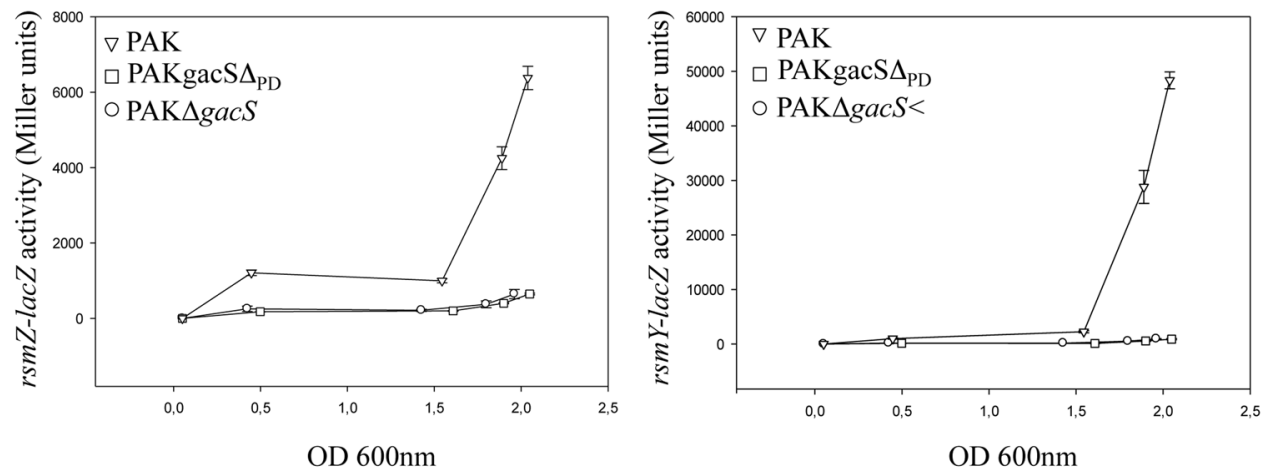

b.

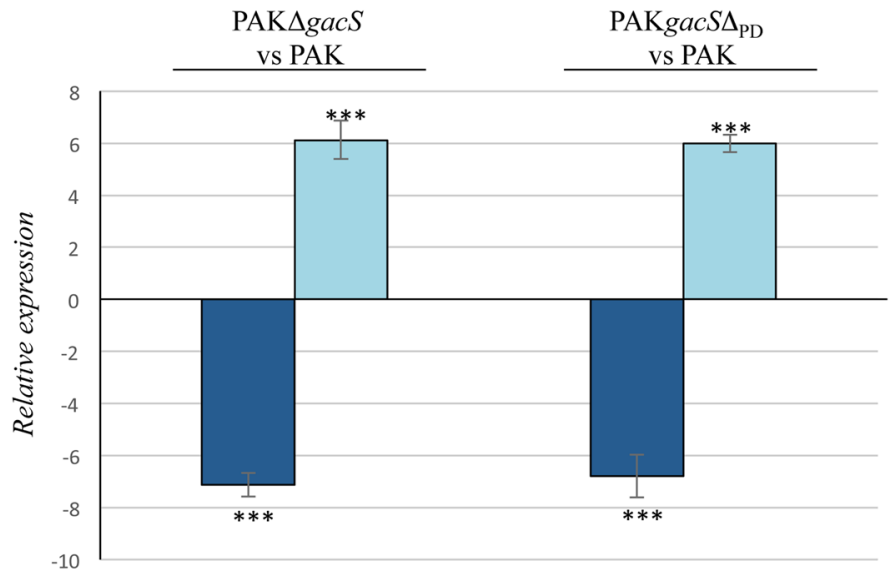

Figure 2. Effect of the deletion of the GacS detection domain on rsm, T3SS and T6SS gene expression. (a) Activities of the $r s m Z$-lacZ (left) and $r s m Y$-lacZ (right) transcriptional chromosomal fusions were monitored at different growth stages in the PAK WT (open triangle), PAK $\Delta g a c S$ (open square) or PAKgacS $\Delta_{\mathrm{PD}}$ (open circle) strain. The corresponding $\beta$-galactosidase activities are expressed in Miller units as the mean values (with error bars) of three independent experiments. (b) Transcript levels of VgrG1b (T6SS; dark blue bar) and ExoS (T3SS; light blue bar) were monitored in the PAK, PAK $\Delta$ gacS and PAKgacS $\Delta_{\mathrm{PD}}$ strains using RT-qPCR; fold change is displayed for the two mutant strains compared to PAK strain. *, ** and *** refer to $\mathrm{p}<0.05, \mathrm{p}<0.01$ and $\mathrm{p}<0.001$, respectively, according to the moderated t-tests.

connects $\beta 2$ to $\beta 3$, wraps one face of the $\beta$-sheet and part of the outer face of helix $\alpha 3$ that is tightly packed against the opposite face of the $\beta$-sheet ${ }^{34,35}$ (Fig. 3). Despite the sparse NOE contacts for the major loop region that mainly comprise intra-residue and sequential contacts (Fig. S5), nine long-range NOE distance restraints could be identified between residues from the loop and the $\beta$-sheet (Thr123/Gly93, Thr123/Arg94, His124/Gly93, His124/Arg94, Leu125/Gly93, Leu125/Arg94, Gly131/His97, Gly131/Thr86, Ala139/Trp150).

To evaluate the dynamics behavior of $\mathrm{GacS}_{\mathrm{PD}}$ and its major loop in solution, we determined the NMR relaxations properties on the pico to nanosecond timescale of the backbone amides. Most residues showed $\left\{{ }^{1} \mathrm{H}^{-15} \mathrm{~N}\right\}$ NOE ratio values above 0.8 indicating highly defined structures with low flexibility (Fig. 4 ). In contrast, residues in the major loop (as well as in the N-and C-termini) displayed NOE ratio values below 0.4 together with shorter transversal relaxation time (T1) and longer longitudinal relaxation time (T2), which reflect higher flexibility. These results are in excellent agreement with NOE-based secondary structures and confirm the inherent flexibility of the $\mathrm{GaCS}_{\mathrm{PD}}$ major loop.

Structural comparison evidences a conserved residue pattern despite fold variation. A hidden Markov model (HMM)-based profile search identified several periplasmic domains adopting a PDC fold such as the CitA detector kinase (CitAp domain), the methyl-accepting chemotaxis protein from Geobacter sulfurreducens and the DcuS sensor kinase (DcuSp domain), as the closest structural homologs (HHpred true-positive Prob $>97.4 \%$ Figs 5 and S4). Next, pairwise structural comparison between $\mathrm{GacS}_{\mathrm{PD}}$ and CitAp, DcuSp, the Salmonella typhimurium metal binding domain (PhoQ), the Halorhodospira halophile photoactive yellow protein $(P Y P)$ and the Geobacter sulfurreducens methyl-accepting binding domains (GSU0582 and GSU0935) showed an average rmsd value of $2.78 \pm 0.4 \AA$ for 42 CAs atoms of the central $\beta$-sheet, compared to a value of $2.1 \pm 0.5 \AA$ between various PAS and PDC domains ${ }^{34-42}$. 
a.
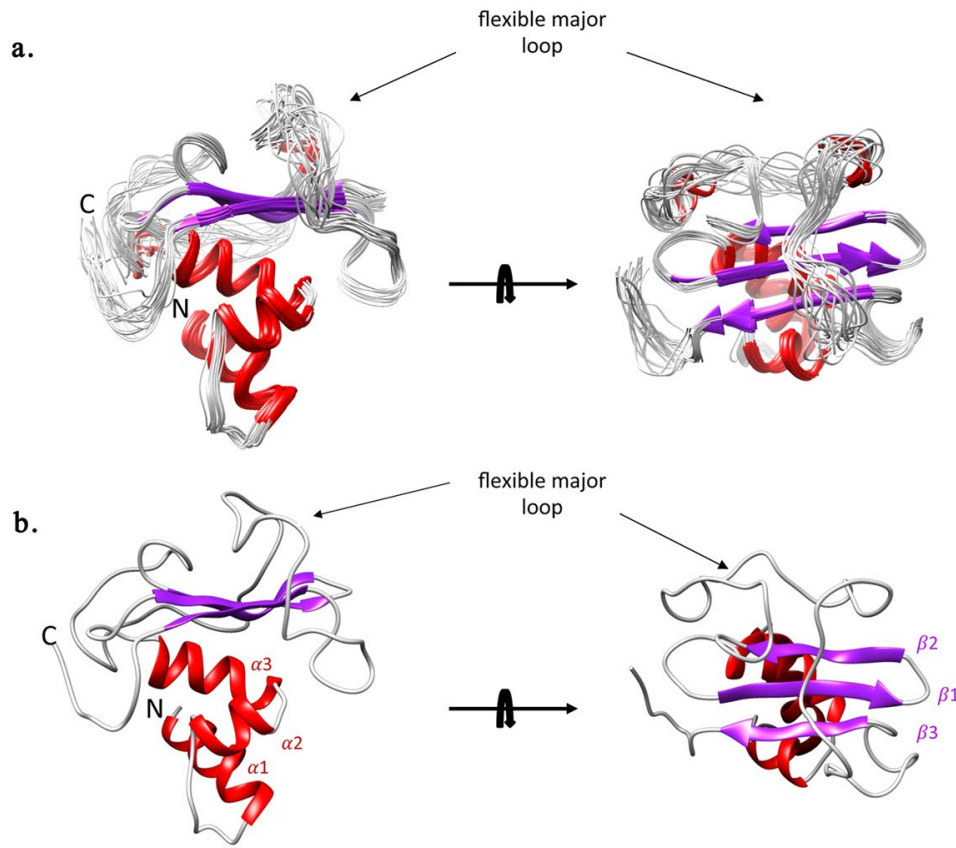

flexible major

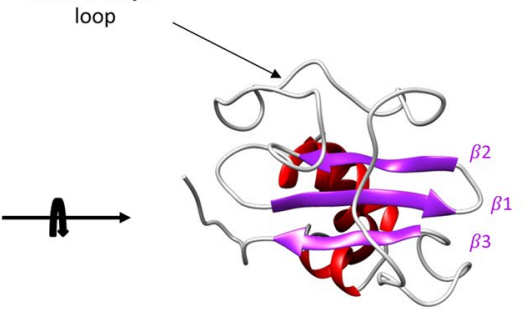

c.

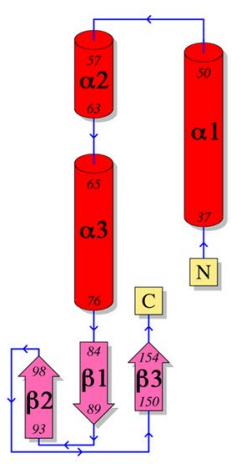

Figure 3. NMR solution structure of $\mathrm{GacS}_{\mathrm{PD}}$. (a) A superimposition of 20 representative structures of $\mathrm{GacS}_{\mathrm{PD}}$ corresponding to the minimal rmsd of all protein backbone $\mathrm{N}, \mathrm{C} \alpha$ and $\mathrm{CO}$ atoms. (b) $\mathrm{GacS}_{\mathrm{PD}}$ lowest-energy structure. The structure contains a central $\beta$-sheet containing three $\beta$-strands $(\beta 1$ 84-89, $\beta 293-98$ and $\beta 3150-$ 154 ) and three $N$-terminal $\alpha$-helices ( $\alpha 138-50, \alpha 2$ 57-63 and $\alpha 365-76)$. A major loop, indicated by a black arrow, links $\beta 2$ to $\beta 3$ and wraps the apical side of the $\beta$-sheet. The $\mathrm{N}$ - and C-termini are labelled. (c) Topology scheme of $\mathrm{GacS}_{\mathrm{PD}}$.

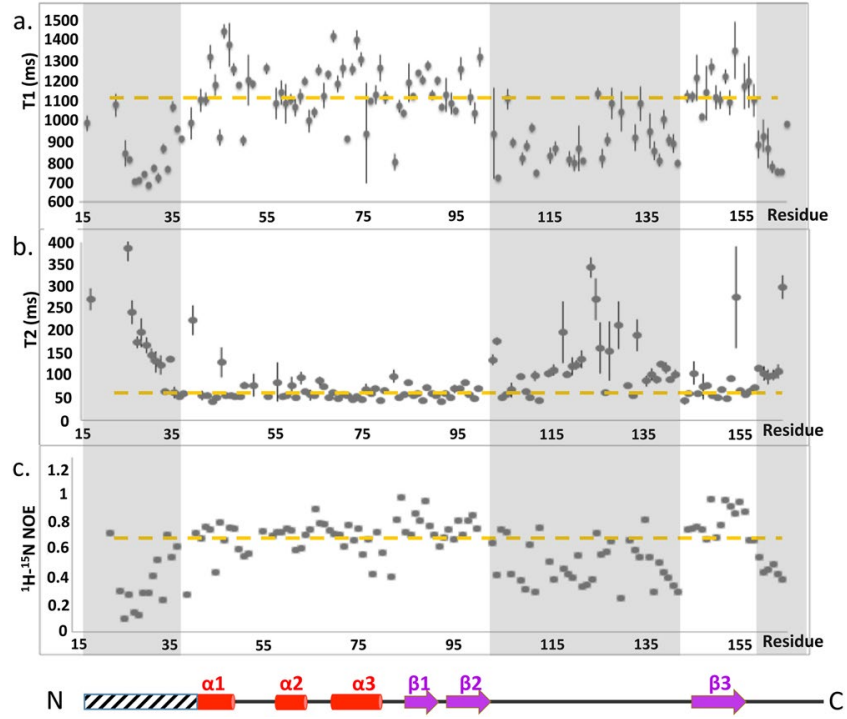

Figure 4. ${ }^{15} \mathrm{~N}$ NMR backbone relaxation data of $\mathrm{GacS}_{\mathrm{PD}}$. (a) Per residue ${ }^{15} \mathrm{~N} \mathrm{~T}_{1}$ longitudinal relaxation times. (b) Per residue ${ }^{15} \mathrm{~N} \mathrm{~T}_{2}$ transverse relaxation times. (c) Per residue heteronuclear NOE ratios along with the location of $\mathrm{GacS}_{\mathrm{PD}}$ secondary structural elements shown as red cylinder for $\alpha$-helix and violet arrow for $\beta$-strand.

Besides this overall fold conservation, the striking structural differences between $\mathrm{GacS}_{\mathrm{PD}}$ and other PDC/PAS detector domains reside in the number of $\beta$-strands from the central $\beta$-sheet and the presence of a major loop (Gly99-Leu148) covering the outer face of the $\beta$-sheet at the apical side of $\mathrm{GacS}_{\mathrm{PD}}$ (Fig. S4). In other PDC-type detector domains, such as CitAp, DcuSp and PhoQ, the corresponding loop shows high variability in length and is often limited to two small $\alpha$-helices containing up to twelve residues that contribute to ligand specificity ${ }^{43}$ (Fig. S4). In fact, an overlay of PDC-containing domain structures reveals that $\mathrm{GacS}_{\mathrm{PD}}$ has the longest, 49-residues length, loop region (Fig. 5a), which exhibits a pronounced flexibility in solution as demonstrated by NMR 


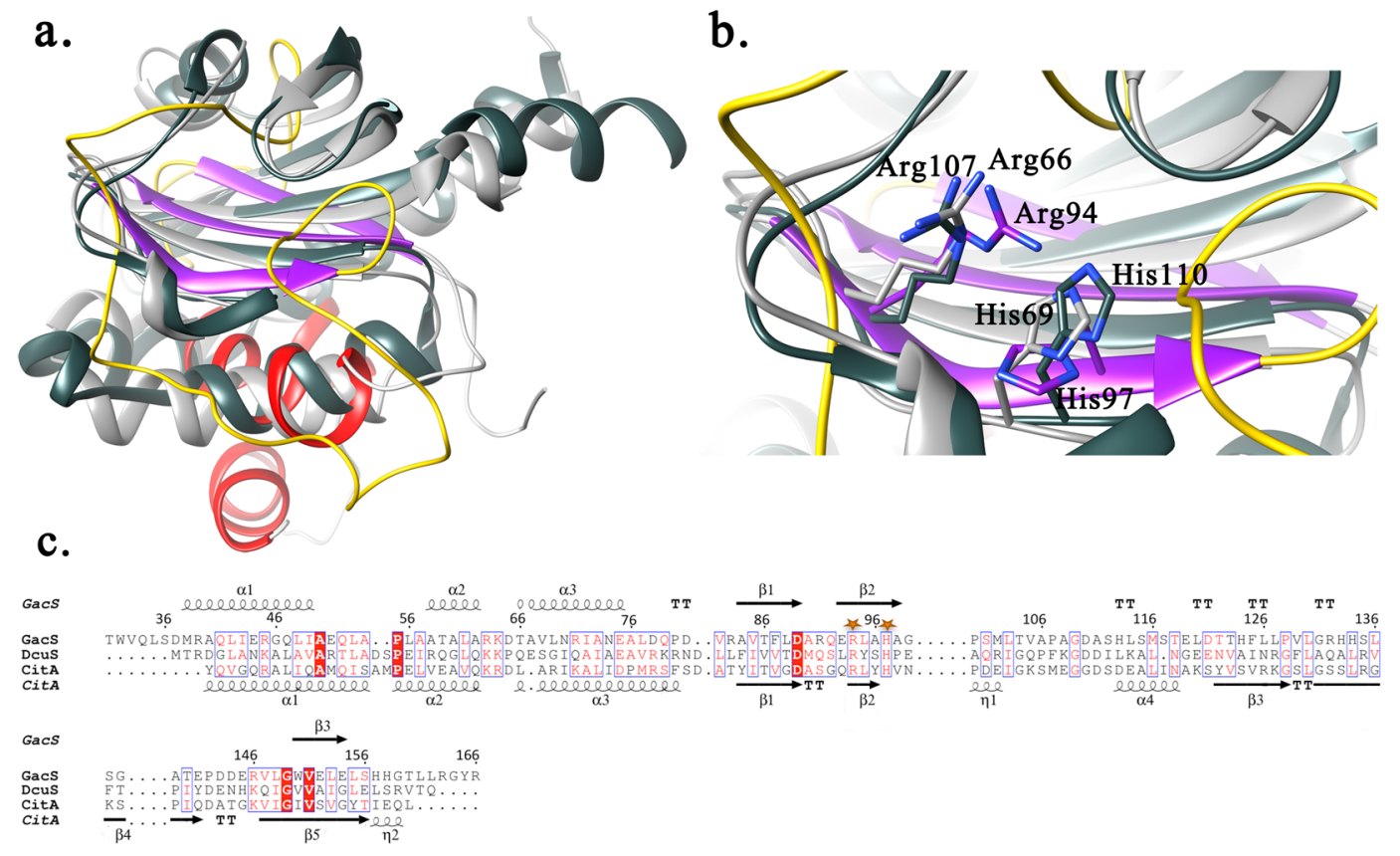

Figure 5. Structural comparison. (a) Superimposition of $\mathrm{GacS}_{\mathrm{PD}}$ (colored secondary structure) and two structural homologues, E. coli DcuSp (dark grey), and K. pneumonia CitAp (light grey). (b) Close-up views of the conservation pattern made by the two positively-charged residues between $\mathrm{GacS}_{\mathrm{PD}}$, CitAp and DcuSp. (c) Structural sequence alignment of $\mathrm{GacS}_{\mathrm{PD}}$, CitAp and DcuSp. The conserved Arg and His residues are highlighted with orange stars.

relaxation data. Such loop flexibility has been reported for other PDC homologues, such as the citrate-free form of CitAp, where a major disordered loop of more than 30 residues, not detected in the crystal structure, showed strong line broadening and low ${ }^{1} \mathrm{H} /{ }^{15} \mathrm{~N}$ signals from backbone amide groups by NMR spectroscopy. Interestingly, stabilization of this loop occurs in the presence of citrate, that also promotes folding of the nearby C-terminal helix ${ }^{44}$. Thus, one could propose that conformational changes of the major loop could also occur in $\mathrm{GacS}_{\mathrm{PD}}$ upon ligand binding, as evidenced for $\mathrm{CitAp}^{44}$.

A sequence alignment of $\mathrm{GacS}_{\mathrm{PD}}$ with the closest structural homologues CitAp and DcuSp evidences conservation of the $\mathrm{GacS}_{\mathrm{PD}}$ Arg94 and His97 pair of interacting residues in these closest structural homologs. In fact, the corresponding residue pairs in DcuSp (Arg107, His110) and CitAp (Arg66, His69) are key residues for binding the negatively-charged C4 and C6-dicarboxyalte ligands, respectively (Fig. 5b and c) ${ }^{35,39}$. Moreover, a multiple sequence alignment using $227 \mathrm{GacS}$ periplasmic detector domains from the Pseudomonas genus reveals conservation of three residues (His97, His133 and Trp150) within the Pseudomonas genus, while Arg94 is not conserved. With the exception of the Trp150 indole ring stably anchored in the hydrophobic core, Arg94, His97 and His124 form a triad of interacting residues on top of the $\beta$-sheet facing the major loop and define a pocket that could represent a putative ligand-binding site (Figs 5 and 6). His124 is a conserved basic residue within the Pseudomonas aeruginosa group and can be substituted with an arginine (Fig. 6b). The solvent-exposed His133 is located within the major loop at one edge of this putative binding site. Given the striking conservation pattern of the Arg-His residue pair in GacS $\mathrm{PD}_{\mathrm{PD}}$, we performed ${ }^{1} \mathrm{H}-{ }^{15} \mathrm{~N}$ HSQC titration experiments of $\mathrm{GacS}_{\mathrm{PD}}$ with a series of related negatively charged molecules, e.g. citrate, fumarate as well as other Krebs cycle intermediates reported to affect the GacS/GacA signaling pathway ${ }^{45}$, 46 , and other molecules or ions (Table S5), but no binding with $\mathrm{GacS}_{\mathrm{PD}}$ was observed.

GacS $_{P D}$ harbors a functional surface region within the major loop. To assess the functional role of these five $\mathrm{GacS}_{\mathrm{PD}}$ residues, we first checked the impact of mutations into alanine on the $\mathrm{GacS}_{\mathrm{PD}}$ fold using NMR ${ }^{1} \mathrm{H}-{ }^{15} \mathrm{~N}$ HSQC experiments. With the exception of the $\mathrm{GacS}_{\mathrm{PD}} \mathrm{W} 150 \mathrm{~A}$ variant that was found to be misfolded due to its major role in $\mathrm{GacS}_{\mathrm{PD}}$ folding and stability, the three fingerprints recorded for a $\mathrm{GacS}_{\mathrm{PD}}$ double mutant (Arg94Ala and His97Ala) and each of the H124A and H133A single mutant did not reveal an alteration of the overall $\mathrm{GacS}_{\mathrm{PD}}$ fold. compared to WT GacS $\mathrm{PD}_{\text {(Fig. S6). }}$

We next generated the four $\operatorname{gacS}_{R 94 A}, \operatorname{gacS}_{H 97 A}, \operatorname{gacS}_{H 124 A}$ and $\operatorname{gacS}_{H 133 A}$ mutant PAK strains to assess the potential role of these residues for biofilm formation. Combined analyzes using crystal violet staining and confocal microscopy revealed that the two GacS His97Ala and His133Ala mutants abolish biofilm formation compared to the WT PAK strain (Fig. 7). The biofilm morphology of these two gac $_{H 97 A}$ and $g a c S_{H 133 A}$ PAK strains exhibits a strong reduction compared to the WT PAK strain (Figs $1 \mathrm{~b}$ and $7 \mathrm{~b}$ ), corresponding to single isolated colonies as observed for the $\triangle$ gacS PAK strain (Fig. 1b). The gacS $_{H 124 A}$ mutant PAK strain showed an altered biofilm morphology compared to the WT strain, indicating a functional role of the pocket-lining His124 residue in biofilm formation. By contrast, the gac $_{R 94 A}$ mutant PAK strain showed biofilm morphology similar to WT PAK strain (Figs 1 and 7b), indicating that mutating Arg94 does not impair biofilm formation. 

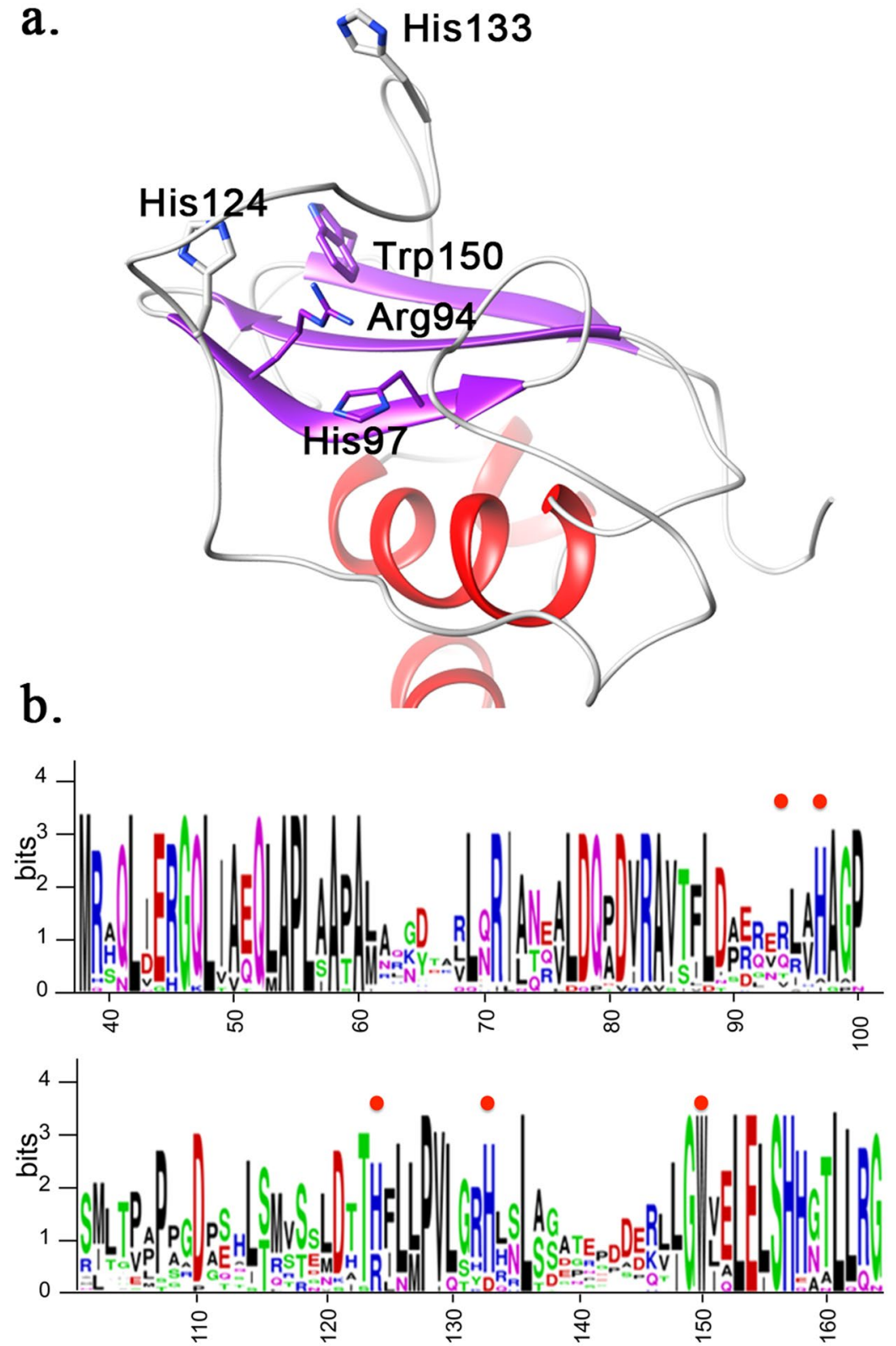

Figure 6. Mutation locations in $\mathrm{GacS}_{\mathrm{PD}}$ solution structure. (a) $\mathrm{A} \mathrm{GacS}_{\mathrm{PD}}$ cartoon representation with the selected mutated residues shown as sticks. (b) Multiple sequence alignment of 227 GacS periplasmic detector domains from the Pseudomonas Genus. The logo representation was generated with the Skylign web-server ${ }^{62}$. Location of the mutated residues (Arg94, His97, His124, His133 and Trp150) is indicated by a red dot.

To further confirm the functional role of these residues, we examined the effect of these four $\mathrm{GacS}_{\mathrm{PD}}$ mutants on the expression of the GacS/GacA TCS target genes, as already performed with the GacS $\Delta_{\mathrm{PD}}$ PAK strain for monitoring $r s m Z / r s m Y$ expression and T6SS and T3SS activation or repression. In turn, the $r s m Y-l a c Z$ and $r s m Z-$ lac $Z$ transcriptional fusions were introduced into the four $\operatorname{gacS}_{R 94 A}, \operatorname{gacS}_{H 97 A}$, gac $S_{H 124 A}$ and $\operatorname{gacS}_{H 133 A}$ mutant PAK strains. Expression level of the two RsmY and RsmZ sRNAs, as measured by the $\beta$-galactosidase activity assay at various growth stages, was decreased in the three $\operatorname{gacS}_{H 97 A}, \operatorname{gacS}_{H 124 A}$ and $\operatorname{gacS}_{H 133 A}$ mutant PAK strains by around 4.6-fold, 1.7-fold and 2.2-fold, respectively for RsmZ and around 3-fold, 5.7-fold and 6-fold, respectively for RsmY, compared to the WT PAK strain (Fig. 8a). In parallel we also examined whether the gacS $_{R 94 A}$, gacS $_{H 97 A}$, $\operatorname{gac}_{\mathrm{H124A}}$ and $\operatorname{gacS}_{\mathrm{H133A}}$ mutant strains could affect expression of T3SS and T6SS. By monitoring the expression level of T6SS (vgrG1b) or T3SS (exoS), we found a 6.2, 2.3 and 6.1-fold induction of T3SS associated to a 6.3, 3.8 and 7.1-fold repression of T6SS in the $\operatorname{gacS}_{H 97 A}, \operatorname{gacS}_{H 124 A}$ and $\operatorname{gac}_{H 133 A}$ mutants, respectively (Fig. 8b).

In summary, we unveiled a functional surface region within $\mathrm{GacS}_{\mathrm{PD}}$ involved in the activation of the GacS/ GacA signaling pathway in $P$ aeruginosa, arguing for a functional role of the periplasmic detector domain of

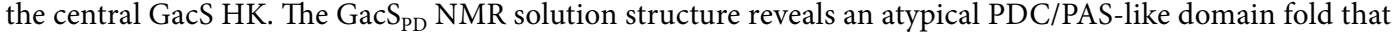
consists of a 3 -stranded $\beta$-sheet flanked by $3 \alpha$-helices and a major loop. This functional region consists of a 


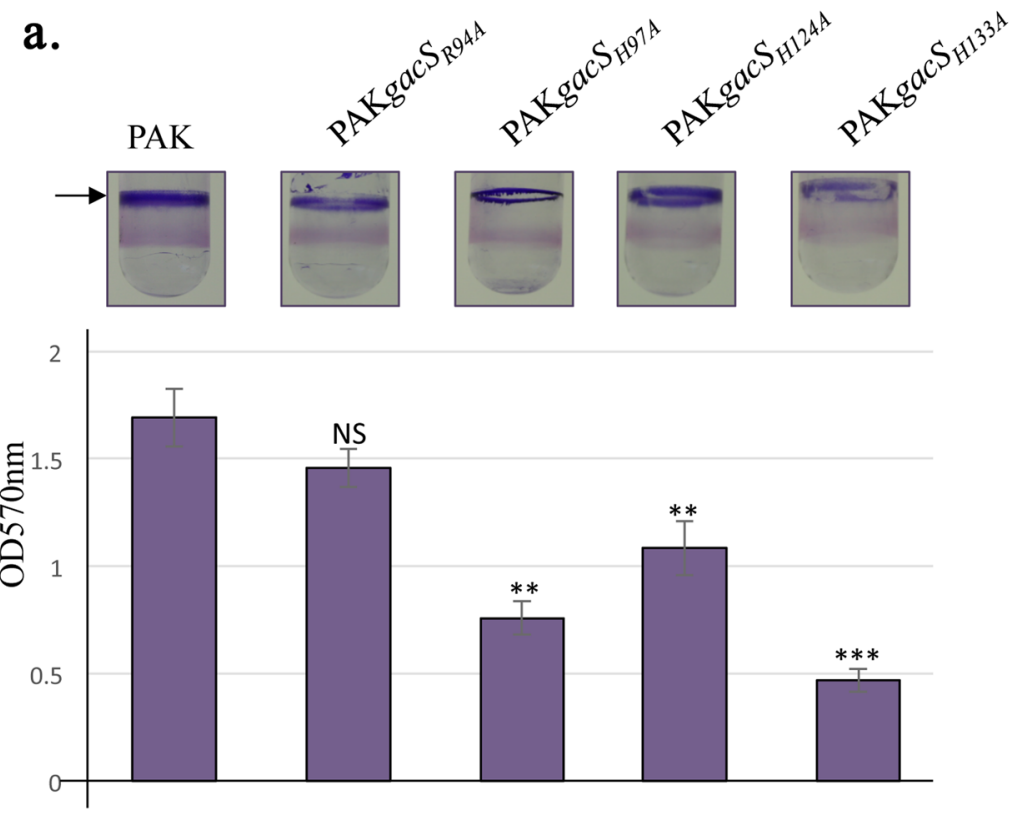

b.
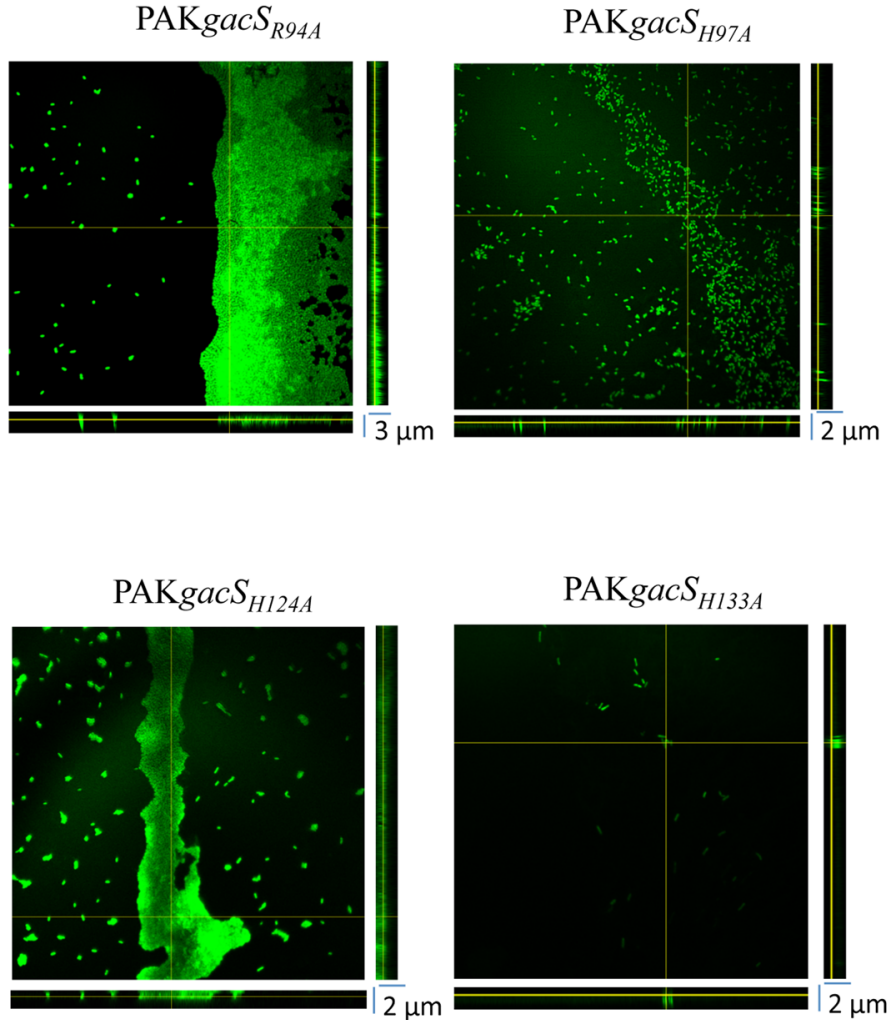

Figure 7. Effect of mutations in the GacS detection domain on biofilm formation. (a) Biofilm production in glass tubes (upper panel) is illustrated and quantified after crystal violet staining (lower panel). The corresponding levels of biofilm production represent means values (with error bars) obtained from three independent experiments. *, $* *, * * *$ and ns referred to $\mathrm{p}<0.05, \mathrm{p}<0.01$ and $\mathrm{p}<0.001$ and non-significant difference, respectively, according to the Wilcoxon-Mann-Whitney tests. (b) Biofilm formation monitored by confocal laser scanning microscopy after $12 \mathrm{~h}$. Extracted $\mathrm{z}$ images and their respective $\mathrm{xy}$ and $\mathrm{xz}$ planes are shown.

positively-charged pocket at the apical side and is defined by at least the three residues His97 H124, and H133 residues, which clearly involves the major loop and one face of the central $\beta$-sheet. Interestingly, while mutation of the invariant Arg94 residue in CitA/DcuS/GacS did not affect the P. aeruginosa adherence, mutation of the 
a.
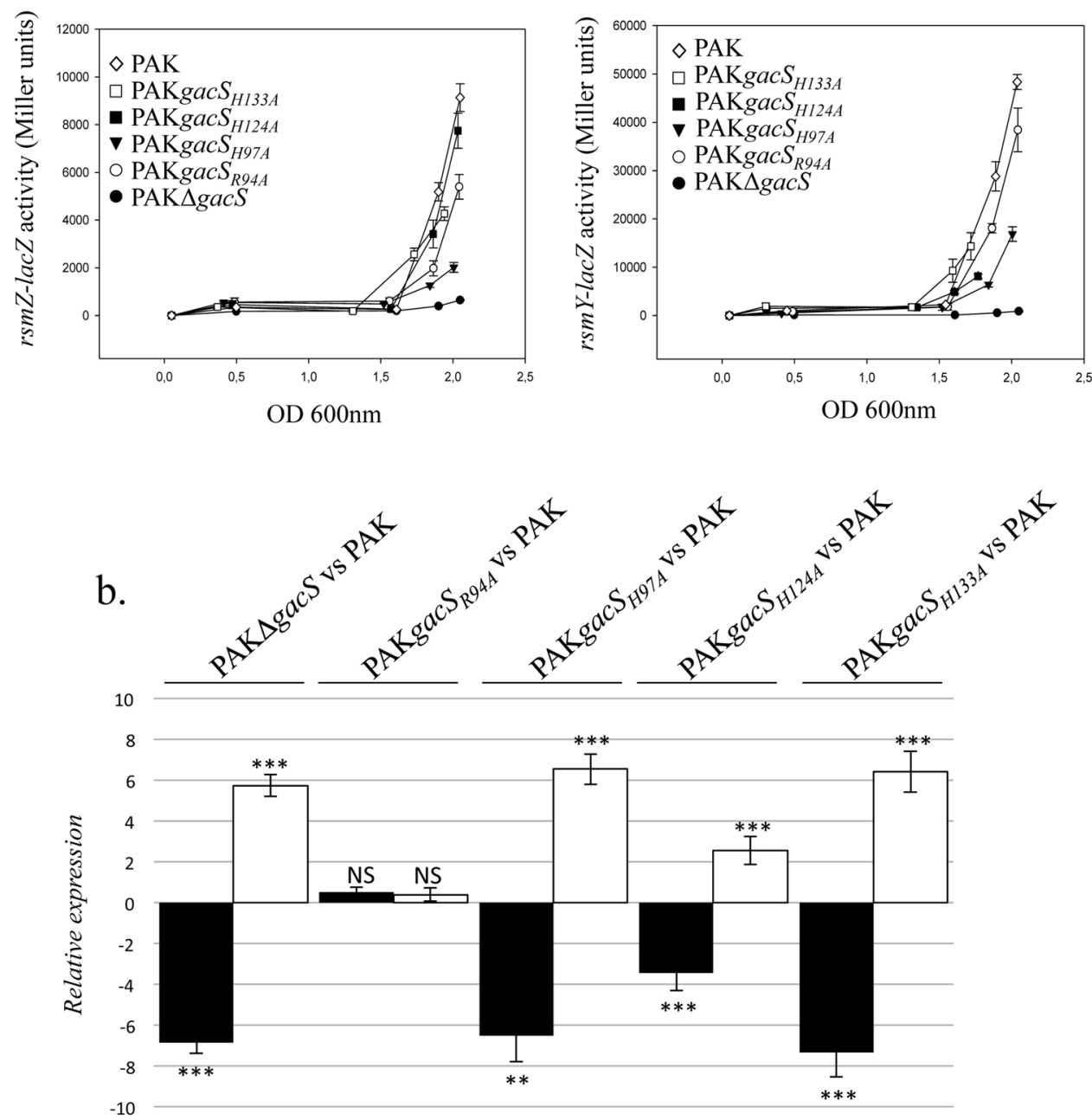

Figure 8. Effect of mutations in the GacS detection domain on rsm genes, T3SS and T6SS expression. (a) Activities of the rsmZ-lacZ (left panel) and rsmY-lacZ (right panel) transcriptional chromosomal fusions were monitored at different growth stages in the $\mathrm{PAK}_{\mathrm{WT}}$, PAK $\triangle$ gacS, $\mathrm{PAKgacS}_{R 94 A}, \mathrm{PAKgacS}_{H 97 A}, \mathrm{PAKgacS}_{H 124 A}$ $P A K g a c S_{H 133 A}$ strains. The corresponding $\beta$-galactosidase activities are expressed in Miller units and correspond to mean values (with error bars) obtained from three independent experiments. (b) Transcript levels of VgrG1b (T6SS; black bar) and ExoS (T3SS; white bar) were monitored in the PAK, PAK $\Delta$ gacS, PAKgacS ${ }_{R 94 A}$, $\mathrm{PAKgacS}_{H 97 A}, \mathrm{PAKgacS}_{H 124 A}$ and $P A \mathrm{Kgac}_{H 133 A}$ strains using RT-qPCR and fold change is displayed for the four mutant strains compared to the PAK strain. *,** and *** refer to $\mathrm{p}<0.05, \mathrm{p}<0.01$ and $\mathrm{p}<0.001$, respectively, according to the moderated t-tests.

three His97, H124 and His133 GacS residues, the latter two being not conserved in CitA/DcuS, severely altered biofilm formation. We could thus propose that the ligand binding site in $\mathrm{GacS}_{\mathrm{PD}}$ does not occur at the same site as the closest structural homologues CitAp and DcuSp. This is consistent with a functional diversity of the GacS periplasmic detector domain acquired during evolution of the PDC/PAS domain-containing HK.

\section{Materials Methods}

Bacterial strains and culture conditions. Strains and plasmids used for this study are listed in Tables S1 and S3, respectively. Strains were grown at $37^{\circ} \mathrm{C}$ in LB medium or in M63 medium supplemented with $1 \mathrm{mM}$ $\mathrm{MgCl}_{2}, 0.5 \%$ casa-aminoacids, $0.2 \%$ glucose. Recombinant plasmids were introduced into $P$. aeruginosa genome through conjugative transfer using pRK2013. Transconjugants were selected on Pseudomonas isolation agar (PIA;Difco Laboratories) supplemented with appropriate antibiotics. Kanamycin $(\mathrm{Km})$ at $50 \mu \mathrm{g} / \mathrm{ml}$ and tetracycline (Tc) at $150 \mu \mathrm{g} / \mathrm{ml}$ supplemented with streptomycin ${ }^{47}$ at $2 \mathrm{mg} / \mathrm{ml}$ were used for E. coli and P. aeruginosa strains, respectively.

Construction of chromosomal variants and mutants. To generate a gacS $\Delta_{\mathrm{PD}} \mathrm{PAK}$ strain harbouring a chromosomal copy of a gacS variant devoid of a periplasmic domain, DNA fragments corresponding to the upstream and downstream sequences (approximately $500 \mathrm{pb}$ ) of the deleted region were amplified from the PAK 
genomic DNA using appropriate oligonucleotide pairs (Table S4). The PCR products were cloned into the pCR2.1 vector (Invitrogen) using the SLIC method. After DNA sequencing, the cloned region was digested by BamH1 and ApaI and inserted into the linearized pKNG101 vector, resulting in the PKNG101 gacS $\Delta_{P D}$ plasmid.

To engineer the four $\operatorname{gac}_{R 94 A}, \operatorname{gac}_{H 97 A}, \operatorname{gacS}_{H 124 A}, \operatorname{gac}_{H 133 A}$, mutant PAK strains, each harbouring a point alanine mutation into a chromosomal copy of the gacS gene, the upstream and downstream sequences (approximately $500 \mathrm{pb}$ ) were amplified from the PAK genomic DNA using the appropriate pairs of primers (Table S4). The forward and reverse PCR products were linked and cloned into the suicide pKNG101 vector using the SLIC strategy, yielding the four $\operatorname{gacS}_{R 94 A}, \operatorname{gacS}_{H 97 A}, \operatorname{gacS}_{H 124 A}$ and $\operatorname{gacS}_{H 133 A}$ PKNG101 plasmids. The resulting suicide plasmid was introduced into the $P$. aeruginosa genomic DNA through conjugative transfer by a three-partner procedure using pRK2013. The deletion mutants were obtained by a double selection: first on LB agar supplemented with Irgasan $(25 \mu \mathrm{g} / \mathrm{mL})$ and streptomycin $(1000 \mu \mathrm{g} / \mathrm{mL})$ at $37^{\circ} \mathrm{C}$ followed by a NaCl-free LB agar containing $6 \%$ sucrose at $30^{\circ} \mathrm{C}$. The genome of each mutant was extracted and the targeted DNA fragment was amplified and verified by sequencing.

RT-qPCR. The WT, $\Delta$ gacS, gacS $\Delta_{\mathrm{PD}}$, gacS $S_{R 94 A}, \operatorname{gac}_{\mathrm{H} 97 \mathrm{~A}}, \operatorname{gacS}_{\mathrm{H124A}}, \operatorname{gac}_{\mathrm{H} 133 \mathrm{~A}}$ PAK strains were grown at $37^{\circ} \mathrm{C}$ under agitation until $\mathrm{OD}_{600}$ reached 4 . Total cellular RNA from a $10 \mathrm{~mL}$ culture medium was isolated using the pureYield RNA midiprep system (Promega), cleaned up and concentrated using the RNeasy kit (Qiagen). RNA yield, purity and integrity were further evaluated on Nanodrop and Experion devices. Reverse transcription was performed on $2 \mu \mathrm{g}$ of RNA using the SuperScript III first-strand synthesis system (Invitrogen). Real-time PCR runs were carried out on a CFX96 Real-Time System (Bio-Rad). Cycling parameters of the real-time PCR were $98^{\circ} \mathrm{C}$ for $2 \mathrm{~min}$, followed by 45 cycles of $98^{\circ} \mathrm{C}$ for $5 \mathrm{~s}$ and $60^{\circ} \mathrm{C}$ for $10 \mathrm{~s}$, ending with a melting curve from $65^{\circ} \mathrm{C}$ to $95^{\circ} \mathrm{C}$ to evaluate amplification specificity. To determine the amplification kinetics of each product, fluorescence derived from incorporation of EvaGreen into the double-stranded PCR products was measured at the end of each cycle using a SsoFast EvaGreen Supermix 2X Kit (Bio-Rad). The data were analyzed using Bio-Rad CFX Manager Software 3.0 (Bio-Rad). The $u v r D$ gene was used as a reference for normalization, in particular because transcription of $u v r D$ is fairly stable in bacteria exposed to antibiotics even at relatively high concentrations ${ }^{48}$.

Biofilm assay. The P. aeruginosa adherence assay was performed in individual glass tubes containing $1 \mathrm{~mL}$ of medium as described previously ${ }^{31}$. Bacteria were grown in $\mathrm{M} 63$ medium supplemented with $1 \mathrm{mM} \mathrm{MgCl} 2,0.5 \%$ casa-amino acids, $0.2 \%$ glucose under static conditions at $30^{\circ} \mathrm{C}$. After 12 hours, the cultures were incubated with $1 \%$ Crystal Violet for $10 \mathrm{~min}$ to stain the attached bacteria and washed twice. Staining was extracted by treatment with $400 \mu \mathrm{L} 95 \%$ ethanol. Subsequently, $600 \mu \mathrm{L}$ of water were added and $\mathrm{OD}_{570}$ was measured. All quantification assays were performed at least in triplicate.

Measurements of $\beta$-galactosidase activity. Strains carrying the lac $Z$ transcriptional fusions were grown at $37^{\circ} \mathrm{C}$ in agitated LB medium. Bacterial cells were collected by centrifugation at different growth times. The $\beta$-galactosidase activity was measured using the method of $\mathrm{Miller}^{49}$.

Confocal laser scanning microscopy analysis of biofilm. P. aeruginosa strains were grown in an 8-well chambered coverglass (Lab-teK II). $200 \mu \mathrm{L}$ of M63 derivate medium containing a bacterial suspension at an $\mathrm{OD}_{600}$ of 0.1 was incubated at $30^{\circ} \mathrm{C}$. After $12 \mathrm{~h}$, the medium was aspired from the corner of each chamber and rinsed twice by adding $200 \mu \mathrm{L}$ of sterile PBS to remove unattached cells. Prior to observation, bacteria were fixed with $4 \%$ paraformaldehyde and stained using $4^{\prime}, 6^{\prime}$-diamidino-2-phenylindole (DAPI) for $15 \mathrm{~min}$. Images were taken at locations of biofilm formation using a confocal laser scanning microscope Confocal Olympus FV1000. Positions were chosen for sagittal sections (xz position) to minimize experimental variability. The number of images for the $3 \mathrm{D}$ biofilm observation within each stack depended on biofilm thickness. All confocal images were analysed using the imageJ software ${ }^{50}$.

Cloning, expression and purification of GacS $_{\mathrm{PD}}$ for structural determination. The DNA sequence coding for the periplasmic detector domain of the GacS HK (Met38-Gly164) was amplified from the extracted PAK genome by using the appropriate primers (Table S4). The PCR products were cloned into the pLic03 vector linearized by BamH1 using the LIC method ${ }^{51}$ yielding the pLic03_GacSsp coding for $\mathrm{GacS}_{\mathrm{PD}}$ fused to a 6xHis tag and a tobacco etch virus (TEV) at the $\mathrm{N}$ terminal region. Expression and purification of $\mathrm{GacS}_{\mathrm{PD}}$ were performed as described ${ }^{33}$.

Structure calculation. The NMR sample contained $0.8 \mathrm{mM}$ protein concentration $(90 \% \mathrm{H} 2 \mathrm{O}, 10 \% \mathrm{D} 2 \mathrm{O})$ in $150 \mathrm{mM} \mathrm{NaCl}, 50 \mathrm{mM}$ phosphate buffer, $\mathrm{pH} 7$. Recorded spectra were analyzed with CARA on the basis of the previously published backbone amide and side chain resonances assignment ${ }^{33}$. The approximate inter-proton distances were obtained from the 2D NOESY, ${ }^{13} \mathrm{C}$ NOESY-HSQC and $3 \mathrm{D}^{15} \mathrm{~N}$ NOESY-HSQC spectra recorded using a mixing time of $150 \mathrm{~ms}$. A total number of 1299 restraints were used for structure calculations. Hydrogen bonds were identified by recording long-range $\mathrm{J}_{\mathrm{NC}}$ HNCO-COSY ${ }^{52}$ and a series of ${ }^{15} \mathrm{~N}-{ }^{1} \mathrm{H}$ HSQC spectra using a sample freshly dissolved in $\mathrm{D}_{2} \mathrm{O} ; 27$ nonexchangeable amides were located in regions of defined secondary structures. Hydrogen bond constraints were introduced using distance restraints in the range of 2.7-3.0 and 1.8-2.0 for $\mathrm{O}-\mathrm{N}$ and $\mathrm{O}-\mathrm{HN}$, respectively. Moreover, 94 additional dihedral restraints were calculated using TALOS + based on ${ }^{1} \mathrm{H}^{\alpha},{ }^{13} \mathrm{C}^{\alpha},{ }^{13} \mathrm{C}^{\beta},{ }^{13} \mathrm{C}^{\prime}$ and ${ }^{15} \mathrm{~N}$ chemical shifts ${ }^{53}$. Input data and structure calculation statistics are summarized in Table S2. The accuracy of the NMR models has been assessed based on the traditional criteria for successful structure calculation using the program CYANA ${ }^{54} .100$ structures were generated and the 20 lowest-energy structures were selected and each subjected to restrained molecular dynamics using the Amber 4.1 force field within the SANDER module of Amber 10. Water molecules were stripped off and energy terms were calculated for the 
protein using AMBER ${ }^{55}$. Non-bonded interaction cutoff was $15 \AA$ for the restrained MD runs. The final structural ensemble was analysed using PROCHECK-NMR ${ }^{56}$. Structure coordinates have been deposited to the Protein Data Bank under accession number 5O7J.

Relaxation study. ${ }^{15} \mathrm{~N} T_{1}, T_{2}$, and NOE NMR relaxation measurements were performed at $25^{\circ} \mathrm{C}$ on a Bruker Avance $600 \mathrm{MHz}$ using a $2 \mathrm{mM} \mathrm{GacS}_{\mathrm{PD}}$ sample $(90 \% \mathrm{H} 2 \mathrm{O}, 10 \% \mathrm{D} 2 \mathrm{O})$ in $150 \mathrm{mM} \mathrm{NaCl}, 50 \mathrm{mM}$ phosphate buffer, pH7.0. $T_{1}$ data and $T_{2}$ data were both acquired with ten relaxation delays $(10,20,50,100,200,300$, 400, 600, 800 and $1000 \mathrm{~ms}$ and 17.6, 35.2, 52.8, 70.4, 88.0, 105.6, 123.2, 140.8, 158.4 and 176.0 ms, respectively). Experimental ${ }^{15} \mathrm{~N}$ heteronucleaur NOE values were determined from the intensity ratios of amide signals of interleaved $2 \mathrm{D}^{1} \mathrm{H}_{-}{ }^{15} \mathrm{~N}$ HSQC spectra with and without a $5 \mathrm{sec}$ saturation period. Relaxation times were calculated as reported by Farrow and coworkers ${ }^{57}$ using an exponential fit of single exponential decays to peak intensity values: $I=I_{0} \exp (-\mathrm{t} / \mathrm{T})$ where $T=T_{1}$ or $T_{2}$, and $I=$ resonance intensity at time $t$. Steady-state ${ }^{1} \mathrm{H}-{ }^{15} \mathrm{~N}$ NOE ratios were calculated using the $r=I / I_{0}$ expression.

Ligand binding using ${ }^{1} \mathrm{H}-{ }^{15} \mathrm{~N}$ HSQC titration. Putative ligand molecules (see Table S5) were tested at $298 \mathrm{~K}$ using $150 \mu \mathrm{M}$ of ${ }^{15} \mathrm{~N}$-labelled $\mathrm{GacS}_{\mathrm{PD}}$ native protein and mutants $\left(50 \mathrm{mM} \mathrm{Na}_{2} \mathrm{HPO}_{4} / \mathrm{NaH}_{2} \mathrm{PO}_{4}\right.$ buffer $\mathrm{pH} 7$, $50 \mathrm{mM} \mathrm{NaCl}$ ) with a ligand concentration range of $0.1-20 \mathrm{mM}$.

Bioinformatics analysis. $227 \mathrm{GacS}$ protein sequence homologues belonging to the Pseudomonas genus were retrieved from Uniprot (ftp://ftp.uniprot.org, Feb 2017) and aligned with Muscle ${ }^{58}$ and downloaded from the Uniprot FTP server (ftp://ftp.uniprot.org) in February, 2017. From the multiple alignments, a selection of GacS periplasmic domains was made with Gblock Server ${ }^{59}$. Maximum likelihood trees were generated with PhyML-SMS ${ }^{60}$ using the LG empirical amino acid substitution model of evolution ${ }^{61}$ and 1000 bootstrap replicates. In parallel, the resulting trees were compared with that obtained from the downloaded $16 \mathrm{~S}$ rRNA sequences. The tree parameters including topology were optimized. The sequences of the periplasmic domains that belong to the same branch as $P$. aeruginosa GacS were retained to generate the sequence logo using the Skylign web-server ${ }^{62}$.

\section{References}

1. Stock, A. M., Robinson, V. L. \& Goudreau, P. N. Two-component signal transduction. Annu Rev Biochem 69, 183-215 (2000).

2. Jung, K., Fried, L., Behr, S. \& Heermann, R. Histidine kinases and response regulators in networks. Curr Opin Microbiol 15, 118-124 (2012).

3. Cheung, J. \& Hendrickson, W. A. Sensor domains of two-component regulatory systems. Current opinion in microbiology 13, $116-123(2010)$.

4. Zhang, Z., Liu, Q. \& Hendrickson, W. A. Crystal structures of apparent saccharide sensors from histidine kinase receptors prevalent in a human gut symbiont. FEBS Journal 281, 4263-4279 (2014).

5. Mitrophanov, A. Y. \& Groisman, E. A. Signal integration in bacterial two-component regulatory systems. Genes Dev 22, 2601-2611 (2008).

6. Murray, T. S., Egan, M. \& Kazmierczak, B. I. Pseudomonas aeruginosa chronic colonization in cystic fibrosis patients. Curr Opin Pediatr 19, 83-88 (2007).

7. Gellatly, S. L. \& Hancock, R. E. Pseudomonas aeruginosa: new insights into pathogenesis and host defenses. Pathog Dis 67, 159-173 (2013).

8. Furukawa, S., Kuchma, S. L. \& O’Toole, G. A. Keeping their options open: acute versus persistent infections. J Bacteriol 188, 1211-1217 (2006).

9. Costerton, J. W., Stewart, P. S. \& Greenberg, E. P. Bacterial biofilms: a common cause of persistent infections. Science 284, 1318-1322 (1999).

10. Mougous, J. D. et al. A virulence locus of Pseudomonas aeruginosa encodes a protein secretion apparatus. Science 312, 1526-1530 (2006).

11. Hood, R. D. et al. A type VI secretion system of Pseudomonas aeruginosa targets a toxin to bacteria. Cell Host Microbe 7, 25-37 (2010).

12. Moscoso, J. A., Mikkelsen, H., Heeb, S., Williams, P. \& Filloux, A. The Pseudomonas aeruginosa sensor RetS switches type III and type VI secretion via c-di-GMP signalling. Environ Microbiol 13, 3128-3138 (2011).

13. Russell, A. B. et al. Type VI secretion delivers bacteriolytic effectors to target cells. Nature 475, 343-347 (2011).

14. Goodman, A. L. et al. A signaling network reciprocally regulates genes associated with acute infection and chronic persistence in Pseudomonas aeruginosa. Dev Cell 7, 745-754 (2004).

15. Ventre, I. et al. Multiple sensors control reciprocal expression of Pseudomonas aeruginosa regulatory RNA and virulence genes. Proc Natl Acad Sci USA 103, 171-176 (2006).

16. Chambonnier, G. et al. The Hybrid Histidine Kinase LadS Forms a Multicomponent Signal Transduction System With the GacS/ GacA two component System in Pseudomonas aeruginosa. Plos genetics (2016).

17. Broder, U. N., Jaeger, T. \& Jenal, U. LadS is a calcium-responsive kinase that induces acute-to-chronic virulence switch in Pseudomonas aeruginosa. Nat Microbiol 2, 16184 (2016).

18. Goodman, A. L. et al. Direct interaction between sensor kinase proteins mediates acute and chronic disease phenotypes in a bacterial pathogen. Genes Dev 23, 249-259 (2009)

19. Kong, W. et al. Hybrid sensor kinase PA1611 in Pseudomonas aeruginosa regulates transitions between acute and chronic infection through direct interaction with RetS. Mol Microbiol 88, 784-797 (2013).

20. Bhagirath, A. Y. et al. Characterization of the Direct Interaction between Hybrid Sensor Kinases PA1611 and RetS That Controls Biofilm Formation and the Type III Secretion System in Pseudomonas aeruginosa. ACS Infect Dis 3, 162-175 (2017).

21. Zschiedrich, C. P., Keidel, V. \& Szurmant, H. Molecular Mechanisms of Two-Component Signal Transduction. J Mol Biol (2016).

22. Cheung, J. \& Hendrickson, W. A. Structural analysis of ligand stimulation of the histidine kinase NarX. Structure 17, 190-201 (2009).

23. Zhang, Z. \& Hendrickson, W. A. Structural characterization of the predominant family of histidine kinase sensor domains. J Mol Biol 400, 335-353 (2010).

24. Vincent, F. et al. Distinct oligomeric forms of the Pseudomonas aeruginosa RetS sensor domain modulate accessibility to the ligand binding site. Environ Microbiol 12, 1775-1786 (2010).

25. Heeb, S. \& Haas, D. Regulatory roles of the GacS/GacA two-component system in plant-associated and other gram-negative bacteria. Molecular plant-microbe interactions 14, 1351-1363 (2001). 
26. Brencic, A. \& Lory, S. Determination of the regulon and identification of novel mRNA targets of Pseudomonas aeruginosa RsmA. Mol Microbiol 72, 612-632 (2009).

27. Friedman, L. \& Kolter, R. Two genetic loci produce distinct carbohydrate-rich structural components of the Pseudomonas aeruginosa biofilm matrix. J Bacteriol 186, 4457-4465 (2004).

28. Vasseur, P., Vallet-Gely, I., Soscia, C., Genin, S. \& Filloux, A. The pel genes of the Pseudomonas aeruginosa PAK strain are involved at early and late stages of biofilm formation. Microbiology 151, 985-997 (2005).

29. Bleves, S., Soscia, C., Nogueira-Orlandi, P., Lazdunski, A. \& Filloux, A. Quorum sensing negatively controls type III secretion regulon expression in Pseudomonas aeruginosa PAO1. J Bacteriol 187, 3898-3902 (2005).

30. Engel, J. \& Balachandran, P. Role of Pseudomonas aeruginosa type III effectors in disease. Curr Opin Microbiol 12, 61-66 (2009).

31. Bordi, C. et al. Regulatory RNAs and the HptB/RetS signalling pathways fine-tune Pseudomonas aeruginosa pathogenesis. Mol Microbiol 76, 1427-1443 (2010).

32. Zuber, S. et al. GacS sensor domains pertinent to the regulation of exoproduct formation and to the biocontrol potential of Pseudomonas fluorescens CHA0. Mol Plant Microbe Interact 16, 634-644 (2003).

33. Ali-Ahmad, A. et al. NMR assignments of the GacS histidine-kinase periplasmic detection domain from Pseudomonas aeruginosa PAO1. Biomol NMR Assign (2016).

34. Möglich, A., Ayers, R. A. \& Moffat, K. Structure and signaling mechanism of Per-ARNT-Sim domains. Structure 17, 1282-1294 (2009).

35. Cheung, J. \& Hendrickson, W. A. Crystal structures of C4-dicarboxylate ligand complexes with sensor domains of histidine kinases DcuS and DctB. J Biol Chem 283, 30256-30265 (2008).

36. Cho, U. S. et al. Metal bridges between the PhoQ sensor domain and the membrane regulate transmembrane signaling. J Mol Biol 356, 1193-1206 (2006)

37. Pokkuluri, P. R. et al. Structures and solution properties of two novel periplasmic sensor domains with c-type heme from chemotaxis proteins of Geobacter sulfurreducens: implications for signal transduction. J Mol Biol 377, 1498-1517 (2008).

38. Borgstahl, G. E., Williams, D. R. \& Getzoff, E. D. 1.4 A structure of photoactive yellow protein, a cytosolic photoreceptor: unusual fold, active site, and chromophore. Biochemistry 34, 6278-6287 (1995).

39. Reinelt, S., Hofmann, E., Gerharz, T., Bott, M. \& Madden, D. R. The structure of the periplasmic ligand-binding domain of the sensor kinase CitA reveals the first extracellular PAS domain. J Biol Chem 278, 39189-39196 (2003).

40. Cheung, J., Bingman, C. A., Reyngold, M., Hendrickson, W. A. \& Waldburger, C. D. Crystal structure of a functional dimer of the PhoQ sensor domain. J Biol Chem 283, 13762-13770 (2008).

41. Zhou, Y. F. et al. C4-dicarboxylates sensing mechanism revealed by the crystal structures of DctB sensor domain. J Mol Biol 383, 49-61 (2008).

42. Affandi, T., Issaian, A. V. \& McEvoy, M. M. The Structure of the Periplasmic Sensor Domain of the Histidine Kinase CusS Shows Unusual Metal Ion Coordination at the Dimeric Interface. Biochemistry 55, 5296-5306 (2016).

43. Shah, N. et al. Reductive evolution and the loss of PDC/PAS domains from the genus Staphylococcus. BMC Genomics 14, 524 (2013).

44. Sevvana, M. et al. A ligand-induced switch in the periplasmic domain of sensor histidine kinase CitA. J Mol Biol 377, 512-523 (2008).

45. Takeuchi, K. et al. Small RNA-dependent expression of secondary metabolism is controlled by Krebs cycle function in Pseudomonas fluorescens. J Biol Chem 284, 34976-34985 (2009).

46. Dacheux, D. et al. Activation of the Pseudomonas aeruginosa type III secretion system requires an intact pyruvate dehydrogenase aceAB operon. Infect Immun 70, 3973-3977 (2002).

47. Smith, H. Questions about the behaviour of bacterial pathogens in vivo. Philos Trans R Soc Lond B Biol Sci 355, 551-564 (2000).

48. Jo, J. T., Brinkman, F. S. \& Hancock, R. E. Aminoglycoside efflux in Pseudomonas aeruginosa: involvement of novel outer membrane proteins. Antimicrob Agents Chemother 47, 1101-1111 (2003).

49. Sambrook, J., Fritsch, E. F. \& Maniatis, T. Molecular cloning: a laboratory manual (Cold spring harbor laboratory press, 1989).

50. Schneider, C. A., Rasband, W. S. \& Eliceiri, K. W. NIH Image to ImageJ: 25 years of image analysis. Nature methods $9,671-675$ (2012).

51. Aslanidis, C. \& de Jong, P. J. Ligation-independent cloning of PCR products (LIC-PCR). Nucleic Acids Res 18, 6069-6074 (1990).

52. Cordier, F. \& Grzesiek, S. Direct observation of hydrogen bonds in proteins by interresidue $3 \mathrm{~h} \mathrm{~J} \mathrm{NC} \mathrm{scalar} \mathrm{couplings.} \mathrm{Journal} \mathrm{of} \mathrm{the}$ American Chemical Society 121, 1601-1602 (1999).

53. Shen, Y., Delaglio, F., Cornilescu, G. \& Bax, A. TALOS +: a hybrid method for predicting protein backbone torsion angles from NMR chemical shifts. J Biomol NMR 44, 213-223 (2009).

54. Güntert, P., Mumenthaler, C. \& Wüthrich, K. Torsion angle dynamics for NMR structure calculation with the new program DYANA. J Mol Biol 273, 283-298 (1997).

55. Go tz, A. W. et al. Routine microsecond molecular dynamics simulations with AMBER on GPUs. 1. Generalized born. Journal of chemical theory and computation 8, 1542-1555 (2012).

56. Laskowski, R. A., Rullmannn, J. A., MacArthur, M. W., Kaptein, R. \& Thornton, J. M. AQUA and PROCHECK-NMR: programs for checking the quality of protein structures solved by NMR. J Biomol NMR 8, 477-486 (1996).

57. Farrow, N. A. et al. Backbone dynamics of a free and a phosphopeptide-complexed Src homology 2 domain studied by 15N NMR relaxation. Biochemistry 33, 5984-6003 (1994).

58. McWilliam, H. et al. Analysis Tool Web Services from the EMBL-EBI. Nucleic Acids Res 41, W597-W600 (2013)

59. Castresana, J. Selection of conserved blocks from multiple alignments for their use in phylogenetic analysis. Mol Biol Evol 17, 540-552 (2000)

60. Guindon, S., Delsuc, F., Dufayard, J. F. \& Gascuel, O. Estimating maximum likelihood phylogenies with PhyML. Methods Mol Biol 537, 113-137 (2009).

61. Le, S. Q. \& Gascuel, O. An improved general amino acid replacement matrix. Mol Biol Evol 25, 1307-1320 (2008)

62. Wheeler, T. J., Clements, J. \& Finn, R. D. Skylign: a tool for creating informative, interactive logos representing sequence alignments and profile hidden Markov models. BMC Bioinformatics 15, 7 (2014).

\section{Acknowledgements}

The authors thank Dr. A. Favier (IBS, Grenoble) and the TGIR-RMN-THC FR3050 CNRS (Grenoble, France) for data collection, and Dr. E. Goemaere for cloning advice in the LIC vectors. We also thank Yann Denis for technical assistance at the transcriptome platform of the Institut de Microbiologie de la Méditerranée. This work was supported by the CNRS, the French National Agency for Research (ANR-14-CE09-0005), a joint grant from the VLM and the Gregory Lemarchal association (RF20150501359/1/1/72) and the French Infrastructure for Integrated Structural Biology (FRISBI) ANR-10-INSB-05-01. A. A. Ahmad was a recipient of a PhD grant from the French Ministry of Research/AMU and VLM/Lemarchal association. 


\section{Author Contributions}

A.A.A., F.F. and C.K. experimentation (NMR, mutagenesis), interpretation, manuscript writing. F.V., C.B., Y.B. and F.G. conceptualization, manuscript writing. M.B., O.B. and G.D.P experimentation (NMR, bioinformatics, microscopy).

\section{Additional Information}

Supplementary information accompanies this paper at doi:10.1038/s41598-017-11361-3

Competing Interests: The authors declare that they have no competing interests.

Publisher's note: Springer Nature remains neutral with regard to jurisdictional claims in published maps and institutional affiliations.

(c) (i) Open Access This article is licensed under a Creative Commons Attribution 4.0 International

License, which permits use, sharing, adaptation, distribution and reproduction in any medium or format, as long as you give appropriate credit to the original author(s) and the source, provide a link to the Creative Commons license, and indicate if changes were made. The images or other third party material in this article are included in the article's Creative Commons license, unless indicated otherwise in a credit line to the material. If material is not included in the article's Creative Commons license and your intended use is not permitted by statutory regulation or exceeds the permitted use, you will need to obtain permission directly from the copyright holder. To view a copy of this license, visit http://creativecommons.org/licenses/by/4.0/.

(C) The Author(s) 2017 